\title{
Study on the Aesthetic Crisis of Chinese Antique Fantasy Movies Since the New Century
}

\author{
Zhuo Li ${ }^{1}$ Zongsheng Yue ${ }^{2, *}$
}

\author{
${ }^{1}$ Guilin University of Electronic Science and technology, Guilin, Guangxi 541004, China \\ ${ }^{2}$ Xiamen University, Xiamen, Fujian 361005, China \\ ${ }^{*}$ Corresponding author. Email:18088772520@163.com
}

\begin{abstract}
Since the new century, Chinese antique fantasy movies have gradually risen and occupied a prominent position in the film market, relying on myths, legends, mythical stories, etc., taking overhead history or fictional space-time as narrative strategy, to show the strange feelings, wonderful view, and strange affairs in the super-real time and space. It greatly satisfied the curiosity of the audience. However, its simple, low, empty, and disordered narrative plot under its gorgeous coat has some shortcomings in the pursuit of modeling and digital special effects. It shows obvious cultural anxiety and value imbalance. If Chinese ancient fantasy films want to maintain their long-term vitality, they should constantly excavate Chinese elements and Chinese stories to create high quality film works.
\end{abstract}

Keywords: Chinese movie, antique fantasy movies, aesthetic crisis

\section{INTRODUCTION}

Since the new century, starting from the "Hero" directed by Zhang Yimou (2002, the time here is release time of the film, similarly hereinafter), the commercial film of our country has been developed by leaps and bounds. The whole film market is showing a prosperous development. Antique fantasy film as an important part, because of its strong audiovisual spectacle, it satisfies the audience's curiosity and creates a box office miracle one after another, greatly activating the Chinese film market. There are THE PROMISE(2005), House of Flying Daggers(2004), Painted Skin series(2008,2012), Legend Of The Demon Cat (2017), Di Renjie (a total of six, 2010-2018 and another 24 large films that Xuke intends to shot), turning on the stage. It is based on the myth, the legend, and classical and strange novel, to show their magic through "people, gods, demons, ghosts, evils, monsters, traversing" and other film elements in that form of an overhead history or a fictitious space-time as a narrative strategy. While it set off a wave of watching the film, it is subject to the critics because of "having a good appearance only".

\section{NARRATION CRISIS: CHAOTIC PLOT AND} SINGLE SUBJECT

Since the 21st century, Harry Potter series (a total of eight, 2001-2011), the Hobbit series(a total of three, 2012-2014), The Lord of the Rings (a total of three, 2001-2003) won lots of fans in the world. These series of films, with beautiful and moving audio-visual experience and the construction of imaginative fantasy world, greatly meet the strange psychology of the audience. Stimulated by western fantasy films and in need of the development of Chinese film genres, Chinese ancient fantasy films have finally emerged in the new century. It takes strange feelings, wonderful view, and strange affairs as narrative elements. With the rich investment of funds, the joining of famous stars and the addition of digital special effects, as well as matured commercial film marketing model, a large number of film viewers, especially young film audiences, enter the cinema to watching. It won a good box office and enlivened the Chinese film market.

As a branch of Chinese fantasy film, most of Chinese ancient fantasy film are in fantasy literature, attracting the audience with the features of the fantasy scene, good and evil will be repaid in kind, love and revenge, the happy ending, and so on. Its outstanding characteristics are "strange" and "fantasy". Unlike the magical or sci-fi films in western fantasy films, which rely on technological elements to promote narration, Chinese antique fantasy movies are "the art of imagination", which purport to express the fantasy world with oriental aesthetic implication with a strong connotation of national culture. Its material are drawn from the myth, the legend, and classical and strange novel, etc. such as Painted Skin series, Mural, and A Chinese Fairy Tale adapted by Strange Stories from a Chinese Studio (commonly known as Ghost and Fairy Stories) written by $\mathrm{Pu}$ Songling, A Chinese Odyssey, Love Of Eternity series, Journey to the West: Conquering the Demons, Journey to the West: The Demons Strike Back, The Monkey King 3, The 
Monkey King, The Monkey King 2 adapted by Journey to the West. And Ancient fantasy films of Monster Hunt, Big Fish \& Begonia and The Great Wall draw lessons from the elements in the Classic of Mountains and Rivers to varying degrees. Fairy warrior, the adventure, the magic, the spirit outline a complicated picture for Chinese antique fantasy film.

Chinese antique fantasy films are still facing obvious problems, for example, the theme of the story is single, the narrative is not satisfactory, the fine special effects are mostly reflected in the trailer, and so on. Especially, the plot of chaotic narrative content, the forced logic, the single theme, the empty connotation have been criticized by the audience and critics. First of all, in order to give the audience a different kind of sensory stimulation, the Chinese fantasy film focuses on the presentation of the wonder scene. To a certain extent, it weakens the strength of the narrative of the story, makes the story serve the picture, and make the plot jump with confused logic. Taking the The Sorcerer and the White Snake for example, in order to create fantasy scenes to attract the attention of the audience, the fantasy film, adapted by Tale Of The White Snake, makes some plots up and adds some optional characters. It seems to be innovative and mixed, but in fact it doesn't do a good job of bucking up the plot of the story, leading to chaos in the plot and lack of emotional basis for the characters, and making the development of the story unreasonable. In addition, some of the antique fantasy movies lead to the confusion of the plot because of the failure of grasping the content of the long fantasy novel. Such as, Legend Of The Demon Cat aroused the dissatisfaction of the original readers and made the audience be at a loss. Moreover, because of unsatisfactory narrative of Surprise, League of Gods, Eternal Love, Ten great III of peach blossom, Swords of Legends, these films were tagged with a "rotten film". Not only is the criticism in the country, but the pace of the world is bound to be limited. And, our antique fantasy movies also lacks epic films, and it has not created a fantasy world that belongs only to the vision of oriental culture. It can be said to be a pity.

Another problem in the narrative of Chinese fantasy films lies in that the theme is single, the story is simple, and there is no profound cultural connotation. For instance, the story of Monster Hunt can be summed up in a single sentence, "it tells a story that Song Tianyin has an accidental pregnancy to give birth to a little monster Hunt who helps Huo Xiaofeng protect and save monsters". THE PROMISE encountered the same embarrassment. Some netizens complained on a network platform that it is "a blood case caused by steamed bread." and specially produced short films whose downloads even exceeded the movie "THE PROMISE" itself on the Internet. This also opened a wave of spoof of Internet users. "Although those movies that taking wonders as advantage, its visual wonders are also built on a persuasive story. Only in this way can wonders get rid of simple dazzling skills and become creative artistic elements."[1] The story is still the most important factor that moves the audience. It is necessary for us to reflect the narrative status of Chinese antique fantasy movies.

\section{IMAGE CRISIS: POOR VISUAL EFFECT, UGLY FOR SURPRISE}

The Chinese fantasy film has a long history and gradually fade out of people's horizons in a certain social environment. However, with China's entry into WTO, the Chinese film market is stimulated by more and more overseas fantasy films. "At the same time, due to the needs of the development of Chinese film types, Chinese fantasy films rise again."[2] as a branch of Chinese fantasy films, although antique fantasy movies, draws lessons from some narrative elements of foreign fantasy films, it seizes more about the excellent traditional Chinese culture to show the local story in line with the aesthetic temperament of the East. Compared with magic, science fiction, vampires and other elements in foreign fantasy movies, there are more Chinese elements in Chinese antique fantasy movies, such as kung fu, magic, supernatural power, immortals, specter and so on by which the oriental charm and the mystique are more prominent.

"Chinese fantasy films offer one visual feast after another to the audience while Its pursuit of strange modeling and the presentation of the spectacle are the two most important features."[3] The ultimate pursuit of the wonders of the picture by antique fantasy movies has become a normalcy. And it gradually evolves from the pursuit of aestheticism to the pursuit of macro scenes. As a member of the blockbuster, with huge amount of money, famous star, famous director, top special effects team, Chinese antique fantasy movies has attracted investors, creators and film audiences to chase after it. And most of the audience was scolding and watching. In addition to the empty narrative and the thin theme, what makes the audience and critics complain is that the visual effect is sloppy and the form design which is neither fish nor fowl and lacks the aesthetic feeling, which can be comparable to the "Wumao special effect". Relying on digital technology to create huge, magnificent wonders is an important factor for fantasy films to attract viewers. After all, antique fantasy movies has not yet achieved excellence in screen production. And because of the repetition of

Li Ya and Tian Yigui, The Miracle Crisis of Chinese Films, MOVIE LITERAIURE, 2017, pp.4-7

2 Niu Mengdi and Huo Yihui. Fantasy movies, how about the future [N]. Guangming Daily, November 8, 2015

Zhou Xian. On spectacle film and visual culture [J]

Literary research. 2005 
the subject matter and the homogenization, it seriously causes the viewer to quickly produce the aesthetic fatigue.

Chinese fantasy films blindly seek "fancy", resulting in the phenomenon of "strange" and "ugly". In particular, the shape of some of the characters, in order to pursue its "fancy", has the form of a "wonderful " modeling that deviates from the current viewer's aesthetic acceptance capability, which makes many of the audience speak bluntly" having no incompetence to appreciate it", for example, the modelling of Wu Zetian performed by Liu Jialing in Detective D, the modelling of Daji performed by Fanbingbing in League of Gods. And ASURA mimics the style of western fantasy movies in terms of clothing, hairstyle, architecture and so on. The absurd shape, neither fish nor fowl, is called "duplicate film" and "garbage" by the audience. In less than three days after its release, it was forced out by public opinion. Chinese antique fantasy movies is too much in pursuit of styling "strange", "ugly", which is contrary to our imagination and aesthetic cognition of traditional culture. It is sure to be resisted and criticized by the audience. Especially when we create some images with "strange" characteristics, we define it as ugly and evil, and rarely give it emotion.

In contrast, looking at the fantasy films of the West, Many characters with "strange" characteristics are not "evil", but very "good", for example, Dobbi in Harry Potter, though ugly in shape, is a family elf of the Malfoy family. But because of its sincere help to Harry Potter, as well as optimistic, kind, lovely characteristics, it won the love of the audience; Although the little aliens in E.Y. Alien are ugly, the audience rated it as "ugly cute" because the creator gave him emotional traits when he created this image. That is, although it is very ugly, but it is very cute. The character of the "strange" (or strange or ugly) in the Chinese antique fantasy movies is the pronoun of the "evil". In general, they are wicked and commit innumerable murders. The authors have little to put into their emotions, but to shape it as a negative image. First of all, , according to the traditional aesthetics, the image of the little Huba is very ugly. However, the creator has put a lot of emotional elements into it, so that the audience agrees with it, accepts the image psychologically, and thinks it is "strange and cute".

\section{THE ESSENCE OF THE CRISIS: CULTURAL ANXIETY AND VALUE IMBALANCE}

Most of the Chinese fantasy films at present is low in storyline with simple lines and careless visual effect. And the actors and actresses are in short supply of heat in their performances. Even some antique fantasy movies miss the elements of Chinese culture and the charm of the East because they cater to or imitate Western fantasy films. In recent years, antique fantasy movies has also followed suit. The plot of the story is routine and the personality of the characters is flat. There are large pieces of leather of antique fantasy movies, but lack of profound humanistic connotation and spiritual core. It is even out of touch with Chinese traditional culture. That is, if we change places where the story takes place and the person's name, it can become a story of another country. Under the influence of such films for a long time, it is inevitable that the Chinese audience, especially the young audience, will lack a correct and rational understanding of the antique fantasy movies and even the Chinese film market and lost under the impact of audio-visual wonders, and think little on reality, human nature and culture in fast image consumption. We must rationally realize that if the current Chinese antique fantasy movies continues to develop, it is likely to enter some kind of crisis dilemma, which is quite disadvantageous to its future development.

Chinese antique fantasy movies pays too much attention to the construction of audio-visual wonders of the film and neglects the expression of the content of the story, which has greatly damaged the original appearance of Chinese antique fantasy movies. In particular, its excessive reliance on hot IP such as West Tour, Ghost Stories, ghosts and monsters, etc. The repetition of the subject matter is bound to make the audience resent it for a certain period of time. "In recent years, Chinese films have been in the crisis of spectacles, which to a certain extent has caused the disadvantages of narrow themes, single ideas, far away from real life and real and vivid characters in Chinese films, and finally led to a serious crisis of noumenon and aesthetics." [4] The blind pursuit of antique fantasy movies by the authors, investors, and the audience puts the whole film market into a strange circle. However, the lack of humanistic connotation of antique fantasy movies makes many film critics worry about its future development. Although the number of Chinese antique fantasy movies is gratifying, it has failed to create a historical and poetic fantasy world. Zhao Weifang once said, "the construction of a huge world view is the core of a good fantasy movie."[5] The current reality is that the whole film market takes the box office first. Huge amounts of money are invested in order to receive the largest amount of box office returns. Therefore, Chinese antique fantasy movies generally hires foreign special effects teams, draws lessons from the elements of western fantasy films, holds grand premiere ceremonies, and submits the same marketing manuscripts to major platforms, and so on. Behind the prosperity, it reflects our cultural anxiety and value imbalance. "In addition to industrial considerations,

Li Ya and Tian Yigui, The Miracle Crisis of Chinese Films, MOVIE LITERAIURE, 2017, pp.4-7

Niu Mengdi and Huo Yihui. Fantasy movies, how about the future [n]. Guangming Daily, November 8, 2015 
blockbuster production in a country is bound to bear the cultural responsibility of shaping the image of national subject and collective spiritual identity. "It is the responsibility of blockbuster production for the construction of contemporary culture to bear the value and characteristics of the traditional culture of our nation, to create the characters with national characteristics and to strengthen the sense of national identity."[6]

In the final analysis, the main root cause of the aesthetic crisis presented by Chinese antique fantasy movies is our mentality that we are too eager to create a antique fantasy movies that can win the approval of the Chinese audience and be loved by the audience of the world. Therefore, we "smartly" mixes all kinds of fantasy elements, even takes the elements of Western fantasy films, then presents them to the audience "in a pot". It produces endemic to a considerable extent. "The rapid development of China's film industry is a good thing, but there is a problem hidden in the rapid development itself, that is, there is bound to be a serious imbalance between the rapid development of the industry and the construction of the content. If there is no sustainable progress of the content industry, no continuous innovation of image expression, what can be used as the "hydrocarbon fuel" for the rapid development of the film industry? This is an unavoidable question."[7] Such an image presentation also profoundly reflects the shortcomings of the current Chinese antique fantasy movies. Our extensive "reference" to the elements of western fantasy films has resulted in a seemingly "cultural mix" characteristics. In fact, it is also a concentrated manifestation of cultural dis-confidence. That is to say, we have serious anxiety in dealing with western culture and Chinese traditional culture. We even took the initiative to give up our cultural identity. Although antique fantasy movies is a fantasy film, it must come from Chinese history (mythology). It is incumbent on us to propagate and carry forward the consciousness of the Chinese nation and the traditional Chinese culture. In the creation of antique fantasy movies, we should consciously strengthen the cultural concept of the Chinese nation and pay attention to the display of "Chinese elements".

\section{CONCLUSION}

Since the 21 st century, world fantasy films have gradually become an important part of commercial blockbusters. Chinese antique fantasy movies has also made some achievements and greatly mobilized the enthusiasm of the domestic audience while created a

6 Yang Junlei, "cultural squint" of Chinese Blockbusters and the mixed culture in Chinese film production [J]. Film art. 2008

Cao Yiping. The awakening of wallywood: referring to the failure of Hollywood in the UK and Hollywood in the Soviet Union [J]. Film art. 2016 kind of carnival "grand scenery" by the whole people. However, the Chinese antique fantasy movies are faced crisis with chaos plot, single theme, poor visual effect, taking strange as ugly, loss of emotion. In film industry, it reflects our cultural anxiety and value imbalance. It's worth thinking about by film practitioners who should consciously absorb nutrients from Chinese traditional culture, make rational use of current technology and create more touching works with local characteristics, and global perspective. Only in this way can we pave the way for Chinese antique fantasy movies to impress the Chinese and go to the world, and create a bright future for the Chinese language antique fantasy movies.

\section{References}

[1] Li Ya and Tian Yigui, The Miracle Crisis of Chinese Films, MOVIE LITERAIURE, 2017, pp.4-7

[2] Niu Mengdi and huoyihui. Fantasy movies, how about the future [N]. Guangming Daily, November 8, 2015

[3] Zhou Xian. On spectacle film and visual culture [J]. Literary research. $2005(03) \mathrm{K}$. Elissa, "Title of paper if known," unpublished

[4] Yang Junlei, "cultural squint" of Chinese Blockbusters and the mixed culture in Chinese film production [J]. Film art. 2008

[5] Cao Yiping. The awakening of wallywood: referring to the failure of Hollywood in the UK and Hollywood in the Soviet Union [J]. Film art. 2016.

[6] Analysis of the development status of China's film market in 2018 and the development trend of China's domestic films in 2019 